\title{
In Vitro Antimicrobial Susceptibility of Penicillinase- Producing and Intrinsically Resistant Neisseria gonorrhoeae Strains
}

\author{
MYRON S. COHEN, ${ }^{1,2 *}$ MARJORIE HUCK COONEY, ${ }^{1}$ ELEANORE BLACKMAN, ${ }^{2}$ AND P. \\ FREDERICK SPARLING ${ }^{1,2}$ \\ Departments of Medicine ${ }^{1 *}$ and Microbiology and Immunology, ${ }^{2}$ University of North Carolina School of \\ Medicine, Chapel Hill, North Carolina 27514
}

Received 10 March 1983/Accepted 18 July 1983

\begin{abstract}
The in vitro susceptibility of penicillinase-producing and intrinsically resistant Neisseria gonorrhoeae strains to 13 antimicrobial agents was tested. Regardless of the type of resistance, these organisms remained quite susceptible to newer cephalosporin agents, including moxalactam, cefoperazone, cefotaxime, and ceftazidime.
\end{abstract}

In recent years, many strains of Neisseria gonorrhoeae have demonstrated increased resistance to penicillin $(1-6,8,9,11-17)$. Resistance to penicillin occurs either because of production of beta-lactamase (penicillinase) or as a result of intrinsic resistance. The latter may reflect an alteration in one or more penicillinbinding proteins $(5,14)$ or a decrease in the permeability of the outer membrane to antibiotics (7). The clinical importance of these observations has prompted a search for safe and effective antibiotic agents. The present study was initiated to compare the activities of several newer antibiotics against both beta-lactamasepositive and -negative penicillin-resistant $N$. gonorrhoeae strains.

The antimicrobial agents employed were donated by or purchased from The Upjohn Co., Kalamazoo, Mich. (spectinomycin); Bristol Laboratories, Syracuse, N.Y. (ampicillin and kanamycin); Nutritional Biochemicals Corp., Cleveland, Ohio (tetracycline); Pfizer, Inc., New York, N.Y. (cefoperazone); HoechstRoussel Pharmaceuticals, Inc., Somerville, N.J. (cefotaxime); Eli Lilly \& Co., Indianapolis, Ind. '(moxalactam, cephalexin, and penicillin G); Schering Corp., Bloomfield, N.J. (penem, Sch 29,482); and Glaxo Group, Research Triangle Park, N.C. (ceftazidime).

A total of 53 strains of $N$. gonorrhoeae were tested. Thirty-one strains were collected from patients with anogenital infections in North Carolina. Among this group, four were beta-lactamase positive as determined by the method of O'Callaghan et al. (10). Nineteen penicillin-resistant isolates, six of which were beta-lactamase positive, were provided by $\mathrm{T}$. Tupasi, University of the Philippines, Manila. The other 13 strains from the Philippines demonstrated intrinsic resistance to penicillin (minimal inhibitory concentration [MIC], $>0.5 \mu \mathrm{g} / \mathrm{ml}$, beta lactamase negative), as did 3 strains donated by $\mathrm{I}$. Lind, Statens Seruminstitut, Copenhagen.

The identity of all isolates was confirmed by growth on gonococcal-base broth (Difco Laboratories, Detroit, Mich.) agar plates, characteristic Gram stain and morphology, positive oxidase reaction, and carbohydrate utilization (glucose but not maltose) (15). Organisms were frozen at $-70^{\circ} \mathrm{C}$ until use in tryptic soy broth (Difco Laboratories, Detroit, Mich.) containing $20 \%$ glycerol ( $\mathrm{vol} / \mathrm{vol})$.

MICs were determined by a modification of the agar dilution method (15). Twofold dilutions of antibiotic were distributed onto chocolate agar supplemented with $1 \%$ Supplement C (Difco). Frozen gonococcal isolates were thawed and grown overnight in antibiotic-free plates and suspended in GC base broth (Difco) to an optical density of 25 to 30 Klett units (Klett-Summerson photoelectric colorimeter), and ca. $10^{3} \mathrm{CFU}$ were inoculated onto plates with a Steers replicator. Cultures were incubated for $24 \mathrm{~h}$ at $37^{\circ} \mathrm{C}$ in a $5 \% \mathrm{CO}_{2}$ atmosphere. The MIC was defined as the lowest concentration of antimicrobial agent that inhibited visible growth on the surface of the agar. $\mathrm{MIC}_{50}$ and $\mathrm{MIC}_{90}$ were the lowest concentrations which inhibited 50 and $90 \%$ of tested strains, respectively.

MICs of the antibiotics used are presented in Tables 1 to 3. Gonococcal strains inhibited by only $0.5 \mu \mathrm{g}$ or more of penicillin $\mathrm{G}$ per $\mathrm{ml}$ were identified as resistant (9). Both beta-lactamasepositive and -negative penicillin-resistant strains showed diminished susceptibility to tetracycline, as has been reported previously $(9,12$, 14). Beta-lactamase-producing organisms were 100 -fold less susceptible and intrinsically resist- 
TABLE 1. Susceptibility of 27 penicillin-susceptible N. gonorrhoeae isolates to 13 antibiotic agents ${ }^{a}$

\begin{tabular}{lcccc}
\hline \multirow{2}{*}{ Drug } & \multicolumn{5}{c}{ MIC $(\mu \mathrm{g} / \mathrm{ml})$} \\
\cline { 2 - 5 } & Range & $50 \%$ & $90 \%$ & Modal \\
\hline Penicillin & $0.008-0.5$ & 0.03 & 0.25 & 0.015 \\
Ampicillin & $0.03-0.5$ & 0.06 & 0.25 & 0.06 \\
Piperacillin & $0.002-0.12$ & 0.008 & 0.12 & 0.008 \\
Tetracycline & $0.06-2.0$ & 0.25 & 0.5 & 0.25 \\
Kanamycin & $4.0-50.0$ & 8.0 & 25.0 & 8.0 \\
Spectinomycin & $16.0-50.0$ & 25.0 & 50.0 & 25.0 \\
Cephalexin & $0.008-8.0$ & 1.0 & 4.0 & 0.5 \\
Cefoxitin & $0.12-4.0$ & 0.25 & 2.0 & 0.25 \\
Moxalactam & $0.002-0.12$ & 0.008 & 0.06 & 0.004 \\
Cefoperazone & $0.001-0.12$ & 0.008 & 0.06 & 0.008 \\
Cefotaxime & $0.001-0.06$ & 0.004 & 0.015 & 0.002 \\
Ceftazidime & $0.008-0.25$ & 0.015 & 0.12 & 0.008 \\
Penem & $0.008-0.12$ & 0.03 & 0.12 & 0.03 \\
\hline
\end{tabular}

a All isolates were from North Carolina.

ant organisms were 10-fold less susceptible to piperacillin than were penicillin-sensitive gonococci, consistent with earlier (somewhat conflicting) studies of this agent $(1,6,16)$.

All isolates tested were susceptible to spectinomycin, cefoxitin, and third-generation cephalosporins, including cefotaxime, cefoperazone, moxalactam, ceftazidime, and penem. Penicillin-resistant isolates generally required somewhat greater concentrations of cephalosporin than did penicillin-susceptible isolates, although ceftazidime and penem were only slightly less active against either penicillinase-producing (Table 2) or intrinsically penicillin-resistant isolates (Table 3) than they were against penicillin-susceptible isolates (Table 1). Cefotaxime was inhibitory at a slightly lower concentration than either cefoperazone or moxalactam, as reported

TABLE 2. Susceptibility of 10 penicillinaseproducing $N$. gonorrhoeae isolates to 13 antibiotic agents $^{a}$

\begin{tabular}{lcccc}
\hline \multirow{2}{*}{ Drug } & \multicolumn{5}{c}{ MIC $(\mu \mathrm{g} / \mathrm{ml})$} \\
\cline { 2 - 5 } & Range & \multicolumn{1}{c}{$50 \%$} & \multicolumn{1}{c}{$90 \%$} & Modal \\
\hline Penicillin & $>50.0$ & $>50.0$ & $>50.0$ & $>50.0$ \\
Ampicillin & $\geq 50.0$ & $>50.0$ & $>50.0$ & $>50.0$ \\
Piperacillin & $1.0->50.0$ & 1.0 & 25.0 & 1.0 \\
Tetracycline & $0.5-8.0$ & 1.0 & 8.0 & 8.0 \\
Kanamycin & $16.0-25.0$ & 16.0 & 25.0 & 25.0 \\
Spectinomycin & $25.0-50.0$ & 50.0 & 50.0 & 50.0 \\
Cephalexin & $2.0-25.0$ & 4.0 & 25.0 & 4.0 \\
Cefoxitin & $1.0-4.0$ & 1.0 & 4.0 & 1.0 \\
Moxalactam & $0.03-0.5$ & 0.06 & 0.5 & 0.06 \\
Cefoperazone & $0.03-4.0$ & 1.0 & 2.0 & 1.0 \\
Cefotaxime & $0.004-0.25$ & 0.03 & 0.12 & 0.12 \\
Ceftazidime & $0.015-0.12$ & 0.03 & 0.12 & 0.03 \\
Penem & $0.06-0.25$ & 0.12 & 0.25 & 0.12 \\
\hline
\end{tabular}

a Four isolates were from North Carolina, and six were from the Phillipines.
TABLE 3. Susceptibility of 16 intrinsically penicillin-resistant (non-penicillinase-producing) $N$. gonorrhoeae isolates to 13 antibiotic agents ${ }^{a}$

\begin{tabular}{lcccc}
\hline \multirow{2}{*}{ Drug } & \multicolumn{5}{c}{ MIC $(\mu \mathrm{g} / \mathrm{ml})$} \\
\cline { 2 - 5 } & Range & $50 \%$ & 90\% & Modal \\
\hline Penicillin & $1.0-8.0$ & 2.0 & 4.0 & 2.0 \\
Ampicillin & $0.12-8.0$ & 2.0 & 4.0 & 4.0 \\
Piperacillin & $0.06-1.0$ & 0.5 & 1.0 & 0.5 \\
Tetracycline & $0.5-16.0$ & 4.0 & 8.0 & 8.0 \\
Kanamycin & $16.0-50.0$ & 25.0 & 50.0 & 25.0 \\
Spectinomycin & $25.0-50.0$ & 25.0 & 50.0 & 50.0 \\
Cephalexin & $2.0->50.0$ & 16.0 & $>50.0$ & 16.0 \\
Cefoxitin & $1.0-8.0$ & 4.0 & 8.0 & 8.0 \\
Moxalactam & $0.03-2.0$ & 0.5 & 1.0 & 1.0 \\
Cefoperazone & $0.06-2.0$ & 0.5 & 1.0 & 1.0 \\
Cefotaxime & $0.008-0.5$ & 0.12 & 0.5 & 0.12 \\
Ceftazidime & $0.008-0.5$ & 0.12 & 0.25 & 0.25 \\
Penem & $0.06-0.25$ & 0.12 & 0.25 & 0.25 \\
\hline
\end{tabular}

a Thirteen isolates were from the Phillipines, and three were from Denmark.

previously $(1,9)$. Isolates with intrinsic resistance to penicillin were less susceptible to cefoxitin than were penicillinase-producing strains, as recently noted by Brown et al. (2). Ceftazidime was the most effective agent tested against penicillin-resistant isolates. In vitro differences among newer cephalosporins (e.g., moxalactam, cefotaxime, ceftazidime, and cefoperazone) would not be expected to be of clinical significance, and initial trials of most of these agents have been quite successful (D. J. Lancaster, S. W. Berg, W. O. Harrison, Program Abstr. Intersci. Conf. Antimicrob. Agents Chemother. 20th, New Orleans, La., abstr. no. 675, 1980; $R$. Tight and R. Jones, Program Abstr. Intersci. Conf. Antimicrob. Agents Chemother. 21st, Chicago, Ill., abstr. no. 323, 1981; L. J. Strausbaugh, Program Abstr. Intersci. Conf. Antimicrob. Agents Chemother. 21st, Chicago, Ill., abstr. no. 483, 1981).

Resistance of gonococci to antibiotics is a growing problem, particularly because of increasing prevalence of penicillinase-producing organisms in many parts of the world $(1-4,9$, $11-14,16,17)$. Strains which produce penicillinase may also be intrinsically penicillin resistant (unpublished data); intrinsic (chromosomal) resistance is a well recognized problem $(2,4,5)$. In vitro susceptibility to newer cephalosporin antibiotics of both penicillinase-producing and intrinsically resistant gonococcal isolates from diverse regions of the world suggests that effective therapy for gonorrhoea will be available in the foreseeable future.

This work was supported in part by Public Health Service grant AI15036 from the National Institute of Allergy and Infectious Diseases and by a research grant from Eli Lilly \& Co. M.S.C. is a recipient of the Jefferson-Pilot Fellowship Award. 


\section{LITERATURE CITED}

1. Baker, C. N., C. Thornsberry, and R. N. Jones. 1980. In vitro antimicrobial activity of cefoperazone, cefotaxime, moxalactam (LY127935), azlocillin, mezlocillin, and other $\beta$-lactam antibiotics against Neisseria gonorrhoeae and Haemophilus influenzae, including $\beta$-lactamase-producing strains. Antimicrob. Agents Chemother. 17:757-761.

2. Brown, S., J. Biddle, T. Warnnissorn, K. Pankikabutra, and A. Traisupa. 1982. Antimicrobial resistance of Neisseria gonorrhoeae in Bangkok: is single-drug treatment phase. Lancet ii:1366-1368.

3. Centers for Disease Control. 1980. Penicillinase-producing Neisseria gonorrhoeae-United States, worldwide. Morbid. Mortal. Weekly Rep. 28:85-87.

4. Centers for Disease Control. 1983. Penicillin-resistant gonorrhea-North Carolina. Morbid. Mortal. Weekly Rep. 32:273-275.

5. Dougherty, T. J., A. E. Koller, and A. Tomasz. 1980. Penicillin-binding proteins of penicillin-susceptible and intrinsically resistant Neisseria gonorrhoeae. Antimicrob. Agents Chemother. 18:730-737.

6. Gootz, T. D., C. C. Sanders, and W. E. Sanders, Jr. 1979 In vitro activity of furazlocillin (BAY k 4999) compared with those of mezlocillin, piperacillin, and standard betalactam antibiotics. Antimicrob. Agents Chemother. 15:783-791.

7. Guymon, L. F., D. L. Walstad, and P. F. Sparling. 1978. Cell envelope alterations in antibiotic-sensitive and resistant strains of Neisseria gonorrhoeae. J. Bacteriol. 136:391-401.

8. Hall, W. H., E. H. Schier, and J. E. Maccani. 1979. Comparative susceptibility of penicillinase-positive and -negative Neisseria gonorrhoeae to 30 antibiotics. Antimicrob. Agents Chemother. 15:562-567.
9. Ng, W. S., P. Anton, and K. Arnold. 1981. Neisseria gonorrhoeae strains isolated in Hong Kong: in vitro susceptibility to 13 antibiotics. Antimicrob. Agents Chemother. 19:12-17.

10. O'Callaghan, C. H., A. Morris, S. M. Kirby, and A. H. Shingler. 1972. Novel method for detection of $\beta$-lactamases by using a chromogenic cephalosporin substrate. Antimicrob. Agents Chemother. 1:283-288.

11. Perine, P. L., C. Thornsberry, W. Schalla, J. Biddle, M. D. Siegel, and K. H. Wong. 1977. Evidence for two distinct types of penicillinase-producing Neisseria gonorrhoeae. Lancet ii:993-995.

12. Piot, P., E. Van Dyck, J. Colaert, J.-P. Ursi, E. Bosmans, and A. Meheus. 1979. Antibiotic susceptibility of Neisseria gonorrhoeae strains from Europe and Africa. Antimicrob. Agents Chemother. 15:535-539.

13. Siegel, M. S., C. Thornsberry, W. Biddle, P. R. O'Mara, P. L. Perine, and P. J. Weisner. 1977. Penicillinase-producing Neisseria gonorrhoeae: results of surveillance in the United States. J. Infect. Dis. 137:170-175.

14. Sparling, P. F. 1977. Antibiotic resistance in the gonococcus, p. 112-135. In R. B. Roberts (ed.), The gonococcus. John Wiley \& Sons, Inc., New York.

15. Sparling, P. F., F. A. Sarubbi, Jr., and E. Blackman. 1975. Inheritance of low-level resistance to penicillin, tetracycline, and chloramphenicol in Neisseria gonorrhoeae. J. Bacteriol. 124:740-749.

16. Verbist, L. 1979. Comparison of the activities of the new ureidopenicillins piperacillin, mezlocillin, azlocillin, and Bay k 4999 against gram-negative organisms. Antimicrob. Agents Chemother. 16:115-119.

17. World Health Organization. 1977. A new complication in the fight against gonorrhea. W.H.O. Chronicle 31:38-39. 